\title{
Molecular Characterization and Variation of the Broad bean wilt virus 2 Isolates Based on Analyses of Complete Genome Sequences
}

\author{
Hae-Ryun Kwak ${ }^{1,3}$, Mi-Kyeong Kim ${ }^{1}$, Ye-Ji Lee ${ }^{1}$, Jang-Kyun Seo ${ }^{1}$, Jeong-Soo Kim ${ }^{1}$, Kook-Hyung Kim ${ }^{2}$, \\ Byeongjin $\mathrm{Cha}^{3 *}$ and Hong-Soo Choi ${ }^{1 *}$ \\ ${ }^{1}$ Crop Protection Division, National Academy of Agricultural Science, Suwon 441-707, Korea \\ ${ }^{2}$ Department of Agricultural Biotechnology and Plant Genomics and Breeding Institute, Seoul National University, Seoul 151- \\ 921, Korea \\ ${ }^{3}$ Department of Plant Medicine, Chungbuk National University, Cheongju 361-763, Korea \\ (Received on March 27, 2013; Revised on May 26, 2013; Accepted on May 26, 2013)
}

The full-genome sequences of fourteen isolates of Broad bean wilt virus 2 (BBWV2), collected from broad bean, pea, spinach, bell pepper and paprika plants in Korea during the years 2006-2012, were determined and analyzed comparatively along with fifteen previously reported BBWV2 genome sequences. Sequence analyses showed that RNA-1 and RNA-2 sequences of BBWV2 Korean isolates consisted of 5950-5956 and 3568-3604 nucleotides, respectively. Full-length genome sequencebased phylogenetic analyses revealed that the BBWV2 Korean isolates could be divided into three major groups comprising GS-I (isolates BB2 and RP7) along with isolate IP, GS-II (isolates BB5, P2, P3 and RP3) along with isolate B935, and GS-III including 16 BBWV2 Korean isolates. Interestingly, GS-III appears to be newly emerged and predominant in Korea. Recombination analyses identified two recombination events in the analyzed BBWV2 population: one in the RNA-1 of isolate $K$ and another one in the RNA-2 of isolate XJ143. However, no recombination events were detected in the other 21 Korean isolates. On the other hand, out of 29 BBWV2 isolates, 16 isolates were found to be reassortants, of which each RNA segment (i.e. RNA1 and RNA2) was originated from different parental isolates. Our findings suggested that reassortment rather than recombination is a major evolutionary force in the genetic diversification of BBWV population in Korea.

Keywords : BBWV2, phylogenetic analyses, recombination, reassortment

Broad bean wilt virus (BBWV) is a destructive pathogen in many economically important horticultural and ornamental crops. BBWV is the type species of the genus Fabavirus in

\footnotetext{
*Corresponding author.

Phone) +82-43-261-2557, FAX) +82-43-271-4414

E-mail)bjcha@chungbuk.ac.kr
}

the family Secoviridae (Taylor et al., 1972). It is transmitted by aphids, mostly Aphis gossypii and Myzus persicae, with infection rate of $60-90 \%$ in a nonpersistent manner and has a wide host range (Benner et al., 1985; Brunt et al., 1996). By serological and molecular studies, BBWV isolates are classified into two species, Broad bean wilt virus 1 (BBWV1) and Broad bean wilt virus 2 (BBWV2) (Kobayashi et al., 2003; Uyemoto et al., 1974). Although they show the similar genome structures and functions, the nucleotide (nt) sequence identity between the two BBWV species was limited $(39 \%-67 \%)$. The genome is composed of two single stranded positive-sense RNA molecules, RNA-1 and RNA2 , that are encapsidated separately into icosahedral virions (Lisa et al., 1996). While BBWV1 has been reported mainly in Europe and North America, BBWV2 has a worldwide distribution. In Korea, BBWV1 has not been detected yet, but disease incidences caused by BBWV2 was reported firstly by Lee et al. (1979).

BBWV2 RNA-1 and RNA-2 are approximately $6 \mathrm{~kb}$ and $4 \mathrm{~kb}$ nucleotides (nt) in length, respectively, and each RNA segment contains a single open reading frame (ORF), and thus is translated into a single polyprotein precursor which is further processed by proteolytic cleavage to yield functional proteins. RNA-1 encodes five proteins including cofactor protease (Co-Pro), NTP-binding motif (NTBM), genome-linked viral protein (VPg), protease (Pro) and RNAdependent RNA polymerase (RdRp) while RNA2 encodes three proteins including movement protein (MP), large coat protein (LCP), and small coat protein (SCP) (Goldbach et al., 1995). So far, the complete nt sequences of eight BBWV2 isolates (Ikegami et al., 1998; 2001; Kobayashi et al., 1999; Koh et al., 2001; Kuroda et al., 2000; Lee et al., 2000; Nakamura et al., 1998; Qi et al., 2000a; 2000b) and partial sequences of twenty-five BBWV2 isolates (Ferrer et al., 2011; Kobayashi et al., 1999; 2004; Kondo et al., 2005; Sui et al., 2009) from various host plants have been reported. In Korea, natural infections of BBWV2 on red pepper 
(Lee et al., 2000), broad bean (unpublished), pea (Choi et al., 2001), spinach (Lee et al., 1979), perilla (Choi et al., 2001), lily (Chang et al., 1987), Gentiana spp. (Roh et al, 1998), gladiolus (Park, et al. 1998), and celery (Hahm, et al., 1998) have been reported. In present, disease caused by BBWV2 has increased gradually in pepper plants, i.e. red pepper (Cho et al., 2007), bell pepper, and paprika (Ryu et al., 2009). Nevertheless, molecular characterization of BBWV2 Korean isolates (except K isolate) has not been studied. Recently, we characterized seven BBWV2 isolates obtained from red pepper (Kwak et al., 2013). In this study, we determined complete genome sequences of fourteen BBWV2 isolates collected from various plants including broad bean, pea, spinach, bell pepper, and paprika around the Korean Peninsula during the years 2006-2012. We further analyzed molecular characteristics and genetic structure of BBWV2 Korean isolates in comparison with the previously reported isolates using a range of methods to understand their evolutionary relationships.

\section{Materials and Methods}

Isolates collection. Twenty-one BBWV2 isolates were collected from 6 natural plants in different areas in Korea during the year 2006-2012 based on the symptoms on leaves and fruits. Out of 21 BBWV2 isolates, 3 isolates (BB2, BB5 and BB9) were collected from broad bean (Vicia faba), 2 isolates (P2 and P3) from pea (Pisum

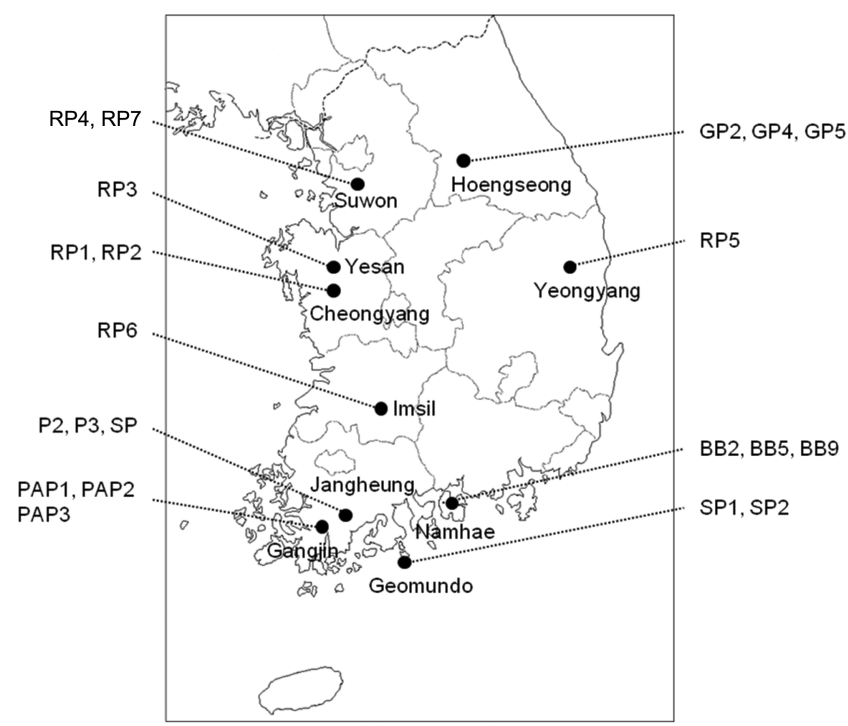

Fig. 1. Geographical locations of the collected BBWV2 isolates in Korea.

Table 1. List of Broad bean wilt virus 2 Korean isolates used in this study

\begin{tabular}{|c|c|c|c|c|c|c|}
\hline \multirow{2}{*}{\multicolumn{2}{|c|}{ Plant isolated from }} & \multirow{2}{*}{ Isolates } & \multirow{2}{*}{$\begin{array}{l}\text { Area } \\
\text { collected }\end{array}$} & \multirow{2}{*}{$\begin{array}{c}\text { Year } \\
\text { collected }\end{array}$} & \multicolumn{2}{|c|}{ NCBI accession No. } \\
\hline & & & & & RNA-1 & RNA-2 \\
\hline \multirow{5}{*}{ Leguminosae } & \multirow{3}{*}{ Vicia faba } & BB2 & Namhae & 2006 & KC625492 & KC625506 \\
\hline & & BB5 & Namhae & 2006 & KC625493 & KC625507 \\
\hline & & BB9 & Namhae & 2006 & KC625494 & KC625508 \\
\hline & \multirow{2}{*}{ Pisum sativum } & $\mathrm{P} 2$ & Jangheung & 2007 & KC625498 & KC625512 \\
\hline & & P3 & Jangheung & 2007 & KC625499 & KC625513 \\
\hline \multirow{3}{*}{ Chenopodiacea } & \multirow{3}{*}{ Spinacia oleracea } & $\mathrm{SP}$ & Jangheung & 2007 & KC625505 & KC625518 \\
\hline & & SP1 & Geomundo & 2007 & KC625503 & KC625516 \\
\hline & & $\mathrm{SP} 2$ & Geomundo & 2007 & KC625504 & KC625517 \\
\hline \multirow{13}{*}{ Solanaceae } & \multirow{7}{*}{ Capsicum anпиит } & RP1 & Cheongyang & 2007 & JX183221 & JX183222 \\
\hline & & $\mathrm{RP} 2$ & Cheongyang & 2007 & JX183223 & JX183224 \\
\hline & & RP3 & Yesan & 2007 & JX183225 & JX183226 \\
\hline & & RP4 & Suwon & 2007 & JX183227 & JX183228 \\
\hline & & RP5 & Yeongyang & 2009 & JX183229 & JX183230 \\
\hline & & RP6 & Imsil & 2010 & JX183231 & JX183232 \\
\hline & & RP7 & Suwon & 2011 & JX183233 & JX183234 \\
\hline & \multirow{3}{*}{$\begin{array}{l}\text { C. annuum var. } \\
\text { gulosum (Paprika) }\end{array}$} & PAP1 & Gangjin & 2010 & KC625500 & KC634010 \\
\hline & & PAP2 & Gangjin & 2010 & KC625501 & KC625514 \\
\hline & & PAP3 & Gangjin & 2011 & KC625502 & KC625515 \\
\hline & \multirow{3}{*}{$\begin{array}{l}\text { C. annuum var. } \\
\text { gulosum }\end{array}$} & GP2 & Hoengseong & 2012 & KC625495 & KC625509 \\
\hline & & GP4 & Hoengseong & 2012 & KC625496 & KC625510 \\
\hline & & GP5 & Hoengseong & 2012 & KC625497 & KC625511 \\
\hline
\end{tabular}


sativum), 3 isolates (SP, SP1 and SP2) from spinach (Spinacia oleracea), 7 isolates (RP1, RP2, RP3, RP4, RP5, RP6 and RP7) from red pepper (Capsicum annum L.), 3 isolates (GP2, GP4 and GP5) from bell pepper (C. annuum var. gulosum), and 3 isolates (PAP1, PAP2 and PAP3) from paprika (C. annuum var. gulosum) (Table 1, Fig. 1). Virus isolates were inoculated to local lesion host, Chenopodium quinoa, reisolated from local lesions at least three times in succession, and propagated in Nicotiana benthamiana.
RT-PCR, cloning and sequencing. Total RNAs were extracted from infected leaf samples by easy-spin ${ }^{\mathrm{TM}}$ total RNA extraction kit (iNtRON, Korea) according to the manufacturer's instructions. RT-PCR was carried out twosteps procedure including RT using AMV reverse transcriptase (Promega, USA) and PCR using LA taq polymerase (TAKARA, Japan). Primer pairs for full-length nt sequence were designed group-specifically for RNA-1 and universally for RNA-2 (Table 2). End sequences of each

Table 2. Primer pairs for full genome sequencing of BBWV2 RNA-1 and RNA-2

\begin{tabular}{|c|c|c|c|c|}
\hline Group & Primer & Sequence $\left(5^{\prime} \rightarrow 3^{\prime}\right)$ & location & Size (nt) \\
\hline \multirow{16}{*}{ I of RNA-1 } & BBWV2 1-1u & AAACAAACAGCTTTCGTTCCG & $19-915$ & 896 \\
\hline & BBWV2 1-1R & TTCCATGCATCGTGTTGGCC & & \\
\hline & BBWV2 1-2F & ATTTCAGGCTCCATTAAAAAGAG & $753-1701$ & 948 \\
\hline & BBWV2 1-2R & TCTATCAACTTCTCCAAAGCC & & \\
\hline & BBWV2 1-3F & GAATGTGATTGCATGGTGGCT & $1515-2400$ & 885 \\
\hline & BBWV2 1-3R & CAAATGAAGTGGCTATGACCGT & & \\
\hline & BBWV2 1-4F & GTACACAAGGTTTAAGGAGCA & $2275-3203$ & 928 \\
\hline & BBWV2 1-4R & CCAAGCACACTTGTGTTCTCA & & \\
\hline & BBWV2 1-3u & TGGGAG(A)TACAAGCAA(G)TGG C & $2867-3888$ & 1021 \\
\hline & BBWV2 1-5R & AAATGCCATTCCTCTGGGG & & \\
\hline & BBWV2 1-6F & GAAGTGCCAGTTTTATGCCGT & $3690-4626$ & 936 \\
\hline & BBWV2 1-6R & TCATTCATGACACACTTGGGC & & \\
\hline & BBWV2 1-7F & GGAGGGATGTTTTACCAGCT & $4476-5252$ & 776 \\
\hline & BBWV2 1-7R & CTATTGCGGAATTCCTTGGC & & \\
\hline & BBWV2 1-8F & TGAATCCAGATGGCACATGG & $5078-5958$ & 880 \\
\hline & BBWV2 1-8R & СССТСАСТАСТGАAАТTTACTTG & & \\
\hline \multirow{14}{*}{ II of RNA-1 } & BBWV2 1-1u & AAACAAACAGCTTTCGTTCCG & $19-1173$ & 1154 \\
\hline & BBWV2 1-1r & CTGAAATAGCTGCCATAGCAG & & \\
\hline & BBWV2 1-2f & TTTGCAGCGTGGATGCC & $883-1981$ & 1098 \\
\hline & BBWV2 1-2r & CTTGTAGCCTGACCAAAAAGG & & \\
\hline & BBWV2 1-3f & GCTGATAGAGTTGCACAATTCAGT & $1774-2850$ & 1076 \\
\hline & BBWV2 1-3r & TACAAATACGCCCTTTGCCA & & \\
\hline & BBWV2 1-4f & GTGGAGCAGATGCAATTGAG & $2603-3664$ & 1061 \\
\hline & BBWV2 1-4r & GAAATACTTTGGGGAATTTCCC & & \\
\hline & BBWV2 1-5f & GATGTGGAAACTTTGCCCAA & $3495-4390$ & 895 \\
\hline & BBWV2 1-5r & TTGCTCACTTCTTCAAACCAAG & & \\
\hline & BBWV2 1-6f & CTTGATCGTGGTCCTGGTGA & $4272-5355$ & 1083 \\
\hline & BBWV2 1-6r & TCCATCTCAAATTTCTCAAGACTT & & \\
\hline & BBWV2 1-7f & TTGGAAATGGCAGAGGCAT & $5239-5958$ & 719 \\
\hline & BBWV2 1-7R & СССТСАСТАСТGАААТTТАСТTG & & \\
\hline \multirow{8}{*}{$\begin{array}{l}\text { Universal of } \\
\text { RNA-2 }\end{array}$} & BBWV2 2-1F & CAAACAGCTTTCGTTCCGAA & $22-949$ & 927 \\
\hline & BBWV2 2-1R & AAGCCATCTGCCACCAATTC & & \\
\hline & BBWV2 2-2F & GCCATGTCAGGTGCTGGA & $801-1702$ & 900 \\
\hline & BBWV2 2-1d & CGCATA(G)GTC(T)TCT(C)GTA(G)GCA(T)GA & & \\
\hline & BBWV2 2-2u & TACAAT(C)TTG(A)CCTGGG(A)CCTAGC & $1377-2496$ & 1119 \\
\hline & BBWV2 2-2r & CATGTTCCCAACCTTTTCAATGT & & \\
\hline & BBWV2 2-3u & ATTT(C)TA(G)GATTTTACT(C)CTC(T)ATGAG & $2348-3511$ & 1163 \\
\hline & BBWV2 2-3d & AGGTCATGGAACCCATTTTAATGG & & \\
\hline
\end{tabular}


Table 3. Database of the complete nucleotide sequences for BBWV isolates

\begin{tabular}{|c|c|c|c|c|c|}
\hline \multirow{2}{*}{ Virus } & \multirow{2}{*}{ Isolate } & \multirow{2}{*}{ Host reported from } & \multirow{2}{*}{ Country reported } & \multicolumn{2}{|c|}{ "NCBI accession No. } \\
\hline & & & & RNA1 & RNA2 \\
\hline \multirow{8}{*}{ BBWV2 } & IP & Capsicum annuum & Japan & AB023484 & AB018698 \\
\hline & ME & Megaskepasma erythrochlamys & Singarpore & NC003003 & NC003004 \\
\hline & IA & Gentiana spp. & Japan & AB051386 & AB032403 \\
\hline & $\mathrm{K}$ & Capsicum annuum & Korea & AF144234 & AF104335 \\
\hline & B935 & Vicia faba & China & AF149425 & AJ132844 \\
\hline & MB7 & Vicia faba & Japan & $\mathrm{AB} 013615$ & AB013616 \\
\hline & $\mathrm{XJ} 14-3$ & Lycopersicon esculentum MILL & China & FN985164 & HQ283389 \\
\hline & PatMMV $^{\mathrm{a}}$ & Pogostemon patchouli & Japan & NC003975 & NC003974 \\
\hline \multirow{2}{*}{ BBWV1 } & PV132 & Spinacia oleracea & USA & AB084450 & AB084451 \\
\hline & Ben & Capsicum annuum & Spain & AY781171 & AY781172 \\
\hline
\end{tabular}

${ }^{\mathrm{a}}$ Patchouli mild mosaic virus; an isolate of BBWV2

RNA segment were obtained with the 5' and 3' rapid amplification of cDNA ends (RACE) protocol (BM, Germany). cDNA clones containing the $5^{\prime}$ end of the genomes were obtained using Xec primers (5'-AAAGAATTCCCCCCCC CCCCC-3'), and BBWV2 5'-RNA1 (5'-GCCATYTCAT TGGCATGGAAAAAGC-3') and BBWV2 5'-RNA2 (5'GAAGGGTGCAACGATATATGCAAATTC-3') primers complementary to nt 384-360 and 424-395, respectively, of BBWV2 stain. In addition, cDNA clones containing the $3^{\prime}$ end of the genomes were obtained using BBWV2 3'-RNA1 (5'-AGGCATATGAGAGAGGAGAG-3') and BBWV2 3'RNA2 (5'-GAAATGGGGAATGTTCATGAGTA-3') primers complementary to nt 5646-5665 and 3269-3291, respectively, and anchor primers (5'-GACCACGCGTATCGAT GTCGACTTTTTTTTTTTTTTTTV-3'). RT-PCR amplified DNA fragments were purified using MEGA quick-spin ${ }^{\mathrm{TM}}$ Kit (iNtRON, Korea) and cloned into pGEM-T easy vector (Promega, USA) according to the manufacturer's instructions followed by transformation into E. coli $\mathrm{DH} 5 \alpha$ strain. Sequencing was done by a commercial company (Genotech, Korea). The resultant sequences were assembled using DNA Star v. 5.02 and have been submitted to GenBank database with accession numbers listed in Table 1.

Sequence and phylogenetic analyses. The complete nt sequences and the deduced amino acid sequences were aligned using Geneious method and ClustalW method in Geneious pro 5 and compared with the previously reported isolates, e.g. IP (Japan, Kobayashi et al., 1999) and ME (Singarpore, Koh et al., 2001) isolates for Group I and IA (Japan, Kuroda et al., 2000), K (Korea, Lee et al., 2000), B935 (China, Qi et al., 2000a; 2000b), MB7 (Japan, Nakamura et al., 1998), XJ14-3 (China, unpublished) isolates and PatMMV (Japan, Ikegami et al., 1998; Ikegami et al., 2001) for Group II and with BBWV1 isolates, PV132 and Ben as outgroup (Table 3). Phylogenetic analyses were performed employing maximum likelihood method implemented in the MEGA 5 (Tamura et al., 2011). All phylogeny tests were done by using the best substitution model for nucleotides/amino acids and 1,000 bootstrap replicates.

Recombination and ressortment analysis. Detection of recombination between 29 BBWV2 isolates was processed by RDP3 program (Recombination Detection Program, ver. 3). The previously saved mega format files which aligning sequences of 29 BBWV2 RNA-1 and RNA-2 segments were opened by RDP3. Then the detection of recombination among those segments, between all RNA-1 segments each, between all RNA-2 segments each and between RNA-1 and -2 each other. Used methods of recombination detections are RDP, GENECONV, BOOTSCAN, MaxChi, Chimaera, and SISCAN methods implemented in the RDP3 program. Parameter was set to default options following the manufacture's recommendation. Then recombination events were computed with highest acceptable P-Value set to 0.01 .

\section{Results}

Genome characterization of BBWV2 Korean isolates. To investigate the genetic diversity of BBWV2 Korean isolates, twenty-one BBWV2 isolates were collected from 6 natural plants (broad bean, pea, spinach, red pepper, bell pepper, and paprika) in 10 areas during the years 20062012: The full-genome sequences of 7 isolates from red pepper from our previous study (Kwak et al., 2013) along with full-genome sequences of 14 additional isolates determined in this study were summarized in Table 1 . The representative symptoms include severe mosaic, vein clearing, stunting on the infected leaves and irregularly shaped coloring, chlorotic spot, and mosaic on the infected fruits 


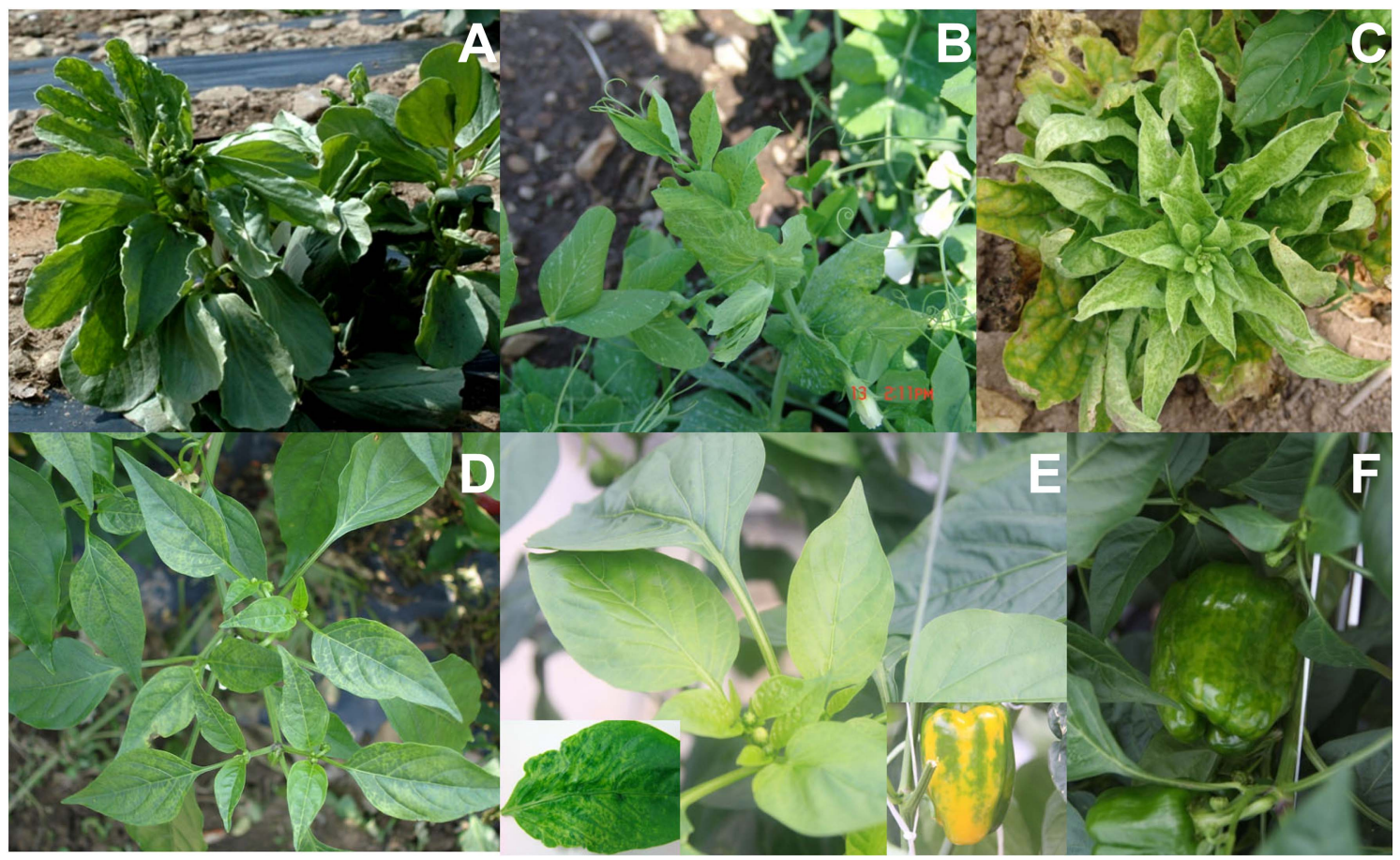

Fig. 2. Symptoms induced by BBWV2 on various host plants infected naturally in Korea. (A) severe mosaic, stunting and leaf curling on Broad bean, (B) mosaic on pea leaves, (C) mosaic on spinach leaves, (D) vein clearing and mosaic on red pepper leaves, (E) severe mosaic on leaves and irregularly shaped coloring on paprika fruits and (F) chlorotic spot and mosaic on bell pepper fruits.

(Fig. 2). The RNA-1 segment of BBWV2 Korean isolates consisted of 5950 to $5956 \mathrm{nt}$ encoding 5 mature proteins including Co-pro (353 or 354 amino acids depending on subgroups), NTBM (582 amino acids), VPg (26 amino acids), Pro (209 amino acids), and RdRp (699 amino acids). The RNA-2 segment consisted of 3568 to 3604 nt encoding 3 mature proteins including MP (465 amino acids), LCP (402 amino acids), and SCP (197 amino acids). The sequences are available in the GenBank database with accession numbers listed in Table 1.

Phylogenetic relationship analysis. The complete nt and deduced amino acid sequences of 21 BBWV2 Korean isolates were analyzed by comparing with eight previously reported BBWV2 isolates (IP, IA, ME, MB7, K, PatMMV, B935, and XJ14-3). Two BBWV1 isolates (PV132 and Ben) were included as outgroup isolates in the phylogenetic analyses. Phylogenetic trees reconstructed using the complete nt sequences revealed that BBWV2 Korean isolates could be divided largely into two groups, Group I and Group II, in both RNA-1 and RNA-2 (Fig. 3). In addition, each group could be subgrouped according to the host plants and/or collected areas. Group I included two isolates (IP and ME) while Group II included six isolates (B935, IA, K, MB7, PatMMV and XJ114) for the RNA-1- and RNA-2-based phylogenetic trees (Fig. 3). For the RNA-1 segment of Korean isolates, four isolates (BB5, RP3, P2, and P3) were classified as Group II and the remains were classified as Group I. Meanwhile, the phylogenetic tree of the RNA-2 segment showed that two Korean isolates, BB2 and RP7, were classified as Group I and the remaining nineteen Korean isolates were classified as Group II. Furthermore, Group II of RNA-2 could be divided into 3 subgroups of II-a, II-b, and II-c. The nineteen Korean isolates, excluding BB2 and RP7, belonged to subgroup IIa along with the Chinese isolate B935.

The phylogenetic trees reconstructed based on the amino acid sequences of the mature proteins which are Co-Pro, NTBM, Pro, RdRp, LCP, and SCP, showed consistent grouping compared with the nucleotide sequence-based trees, but the trees of VPg and MP amino acids showed different patterns in grouping (Fig. 4). The BBWV2 VPg is composed of a short sequence of 26 amino acids and has little variation among isolates. Interestingly, the isolate $\mathrm{K}$ and Chinese isolate XJ14-3 were separately grouped in the trees reconstructed with the Co-Pro or MP amino acid sequences while these two isolates were most closely grouped in the RNA-2 nucleotide-based tree. The majority of RNA-1 genomes of the Korean isolates were grouped into Group I while their RNA-2 genomes were included in Group II. Thus, according to the group-combinations between RNA-1 and RNA-2 segments, BBWV2 could be 

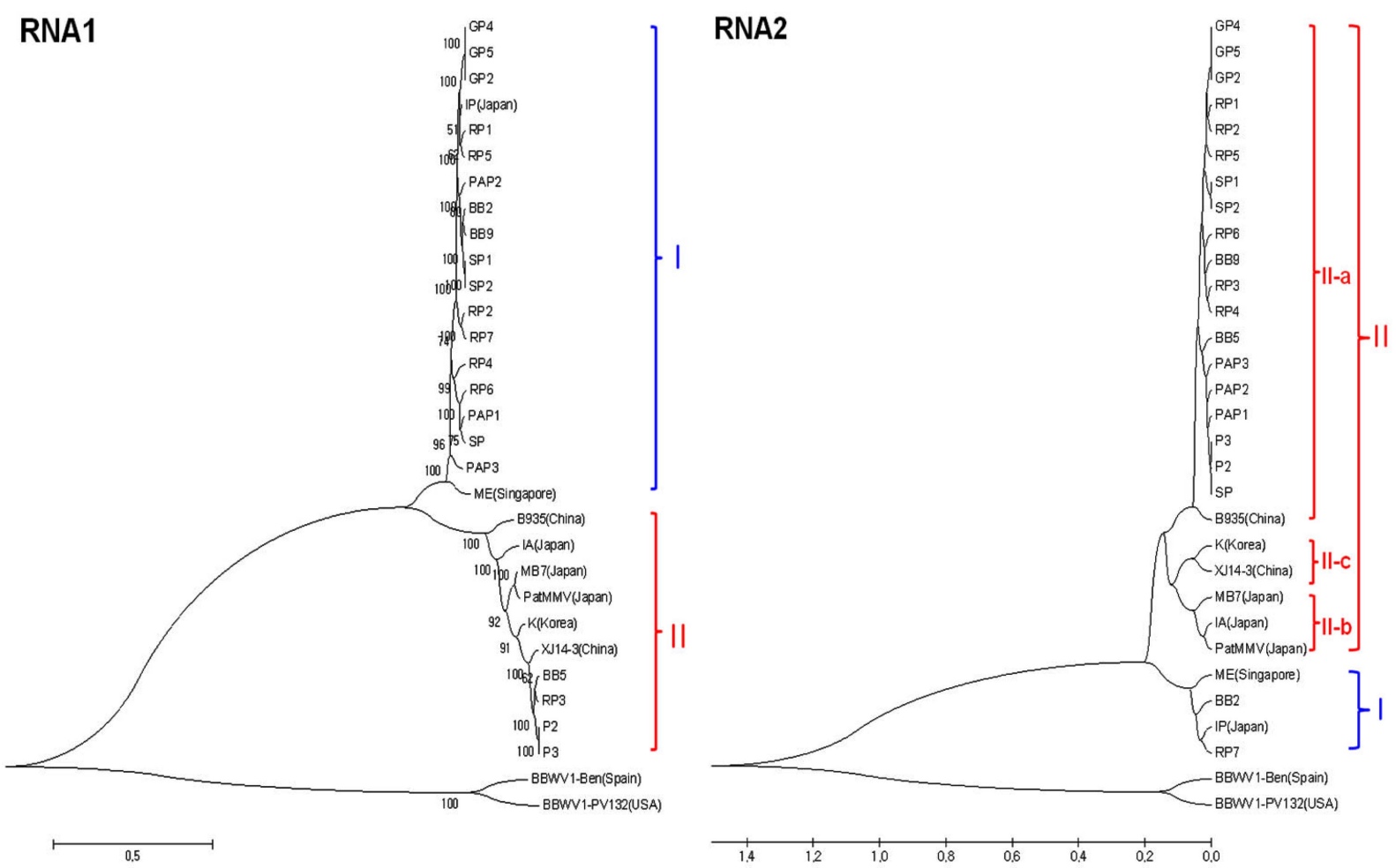

Fig. 3. Phylogenetic trees reconstructed using the complete nucleotide sequences of RNA-1or RNA- 2 of the BBWV2 isolates. The Maximum likehliood method implemented in MEGA 5 was used to reconstruct the phylogenetic trees.

designated as three genetic subpopulations of GS-I (both RNA-1 and RNA-2 genomes belong to Group I), GS-II (both RNA-1 and RNA-2 genomes belong to Group II) and GS-III (RNA-1 and RNA2 genomes belong to Group I and Group II, respectively). Based on this categorization, four isolates (BB2,RP7, IP, and ME) were classified to GS-I, nine isolates (BB5, P2, P3, RP3, B935, IA, MB7, PatMMV, $\mathrm{K}$, and XJ14-3) to GS-II, and the other 15 Korean isolates (BB9, SP, SP1, SP2, RP1, RP2, RP4, RP5, RP6, PAP1, PAP2, PAP3, GP2, GP4, and GP5) to GS-III. The isolates belonging to GS-III have been detected newly and predominantly in Korea.

Sequence comparison. The nucleotide and amino acid sequence identities between BBWV2 isolates were analyzed. The results are summarized in Table 4 and Table 5. For the nt sequences of RNA-1, BB2, which belonged to Group I, showed $98.5 \%$ and $96.5 \%$ nt sequence identities with SP2 and IP, respectively, which belonged to the same group (Fig. 3). On the other hand, BB2 exhibited $78.7 \%$ and 78.2 nt sequence identities with BB5 and $\mathrm{K}$, respectively, which belonged to Group II. In the mean time, BB2 showed 62$63 \%$ nt sequence identity with the BBWV1 isolates (Table 4). For the nt sequence of RNA-2 segment, BB2 showed $90.9 \%$ and $91.4 \%$ nt sequence identities with RP7 and IP, respectively, while it exhibited $78-81 \%$ nt sequence identity with most of isolates in Group II (Table 5).

For the viral proteins encoded in RNA-1, the amino aicd sequence identities between BB2 (as a representative of the Group I isolates) and the Group II isolates were 70-75\% for Co-Pro, $90-92 \%$ for NTBM, $92 \%$ for VPg, $92-93 \%$ for Pro, and $91-92 \%$ for RdRp. The amino acid identity between two groups for Co-Pro was lower than those of the other proteins. Indeed, the amino acid alignment showed that the Co-Pro region contains high amino acid variations among isolates (Fig. 5). For the viral proteins encoded in RNA-2, the amino acid sequence identities between BB2 and the Group II isolates were $85-88 \%$ for MP, $85-94 \%$ for LCP, and $90-94 \%$ for SCP. In addition, the nt sequence identities between BB2 and the Group II isolates for the 5 non-coding region (NCR) and 3 NCR of RNA-2 were relatively lower ( $68-73 \%$ and $69-76 \%$, respectively) than those for the 5 NCR and 3 NCR of RNA1 (74-87\% and $85-89 \%$, respectively).

Recombination and reassortment. Our phylogenetic analyses provided some clues for the possible recombination and reassortment events in the BBWV2 population: i) the inconsistent grouping of the isolate $\mathrm{K}$ and Chinese isolate XJ14-3 in the nucleotide or amino acid sequence-based 

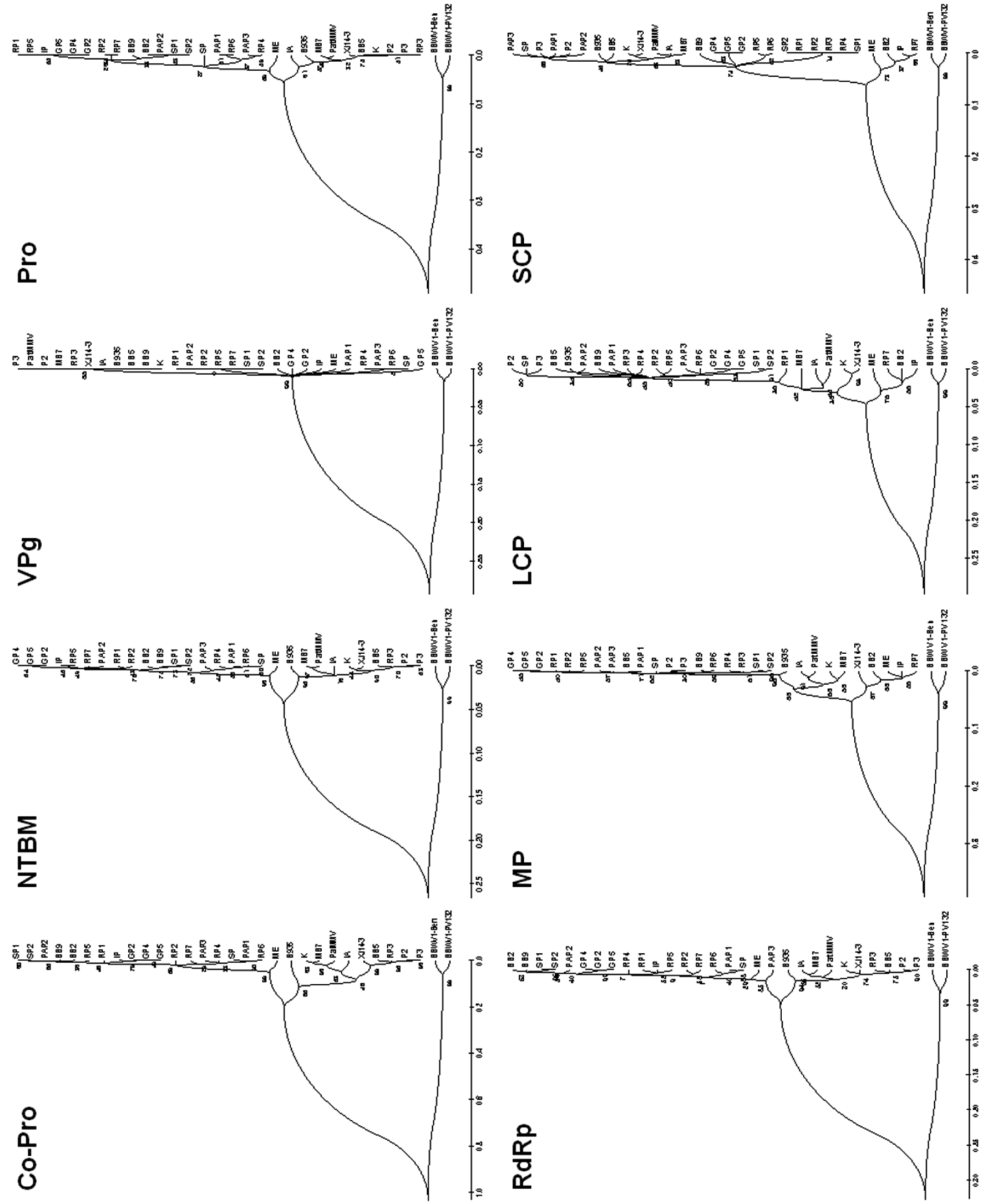

Fig. 4. Phylogenetic trees reconstructed using the amino acid sequences of the viral proteins. Co-Pro, NTBM, VPg, Pro and RdRp are encoded in RNA-1 and MP, LCP and SCP encoded in RNA-2 genome. The Maximum likelihood method implemented in MEGA 5 was used to reconstruct the phylogenetic trees.

phylogenetic trees and ii) the BBWV2 isolates categorized in GS-III by group-combination. Thus, we sought to ex- amine whether recombination and reassortment events have occurred in the BBWV2 population. To this end, the 
Table 4. The nucleotide and amino acid sequence identities (\%) between RNA-1 of the BBWV2 Korean isolate BB2 and RNA-1 of other BBWV isolates

\begin{tabular}{|c|c|c|c|c|c|c|c|c|c|}
\hline Virus & Isolate & $\begin{array}{l}\text { full genome } \\
\text { (nt) }\end{array}$ & 5' NCR (nt) & Co-Pro (aa) & NTBM (aa) & $\operatorname{VPg}(\mathrm{aa})$ & Pro (aa) & $\operatorname{RdRp}(\mathrm{aa})$ & $3^{\prime} \mathrm{NCR}(\mathrm{nt})$ \\
\hline \multirow{28}{*}{ BBWV2 } & BB5 & 78.7 & 86.8 & 73.4 & 91.1 & 92.3 & 93.3 & 91.2 & 87.2 \\
\hline & BB9 & 98.4 & 97.8 & 98.3 & 99.5 & 92.3 & 97.6 & 99.1 & 99.1 \\
\hline & $\mathrm{P} 2$ & 78.9 & 86.9 & 73.7 & 91.4 & 92.3 & 93.3 & 91.7 & 88.5 \\
\hline & P3 & 78.8 & 86.9 & 73.7 & 91.6 & 92.3 & 93.3 & 91.6 & 88.5 \\
\hline & SP & 93.2 & 94.3 & 94.6 & 98.5 & 96.2 & 98.6 & 98.3 & 97.4 \\
\hline & SP1 & 98.4 & 97.8 & 98.3 & 99.0 & 100 & 100 & 99.3 & 98.3 \\
\hline & SP2 & 98.5 & 97.8 & 98.0 & 99.3 & 100 & 99.5 & 99.3 & 98.3 \\
\hline & RP1 & 95.8 & 97.4 & 95.8 & 98.8 & 100 & 99.0 & 98.7 & 99.1 \\
\hline & RP2 & 95.1 & 96.1 & 96.0 & 98.5 & 100 & 99.5 & 98.4 & 97.4 \\
\hline & RP3 & 78.9 & 86.9 & 73.7 & 91.2 & 92.3 & 93.3 & 91.7 & 89.4 \\
\hline & RP4 & 92.7 & 95.7 & 92.1 & 98.3 & 96.2 & 98.6 & 98.1 & 98.3 \\
\hline & RP5 & 95.9 & 96.1 & 96.6 & 99.3 & 100 & 99.0 & 99.0 & 96.6 \\
\hline & RP6 & 92.8 & 93.1 & 93.8 & 98.3 & 96.2 & 98.1 & 98.6 & 99.1 \\
\hline & RP7 & 94.7 & 96.1 & 95.2 & 99.0 & 100 & 99.5 & 98.1 & 96.6 \\
\hline & PAP1 & 93.1 & 95.7 & 94.1 & 98.6 & 96.2 & 98.1 & 98.0 & 98.0 \\
\hline & PAP2 & 96.6 & 96.5 & 97.2 & 99.1 & 100 & 100 & 98.9 & 99.1 \\
\hline & PAP3 & 93.1 & 94.3 & 95.5 & 98.8 & 96.2 & 98.1 & 97.9 & 98.3 \\
\hline & GP2 & 95.7 & 97.8 & 97.5 & 99.1 & 100 & 99.0 & 98.3 & 98.3 \\
\hline & GP4 & 95.7 & 97.8 & 97.5 & 99.1 & 100 & 99.0 & 98.4 & 98.3 \\
\hline & GP5 & 95.7 & 97.8 & 97.5 & 99.1 & 100 & 99.0 & 98.4 & 98.3 \\
\hline & IP & 96.5 & 98.7 & 96.9 & 99.3 & 96.2 & 99.0 & 98.6 & 97.4 \\
\hline & $\mathrm{ME}$ & 90.2 & 91.7 & 90.9 & 97.6 & 92.3 & 94.3 & 96.9 & 88.9 \\
\hline & IA & 78.5 & 86.4 & 75.7 & 92.1 & 92.3 & 92.8 & 91.8 & 88.5 \\
\hline & MB7 & 79.5 & 86.9 & 74.0 & 92.1 & 92.3 & 92.3 & 91.7 & 86.0 \\
\hline & PatMMV & 79.5 & 87.3 & 73.7 & 91.8 & 92.3 & 92.8 & 92.4 & 87.6 \\
\hline & B935 & 78.8 & 86.4 & 74.0 & 91.9 & 92.3 & 93.8 & 91.8 & 88.5 \\
\hline & XJ14-3 & 79.1 & 87.2 & 73.4 & 91.4 & 92.3 & 92.8 & 92.4 & 89.1 \\
\hline & $\mathrm{K}$ & 78.2 & 74.4 & 70.4 & 90.7 & 92.3 & 93.3 & 91.0 & 85.7 \\
\hline \multirow{2}{*}{ BBWV1 } & Ben & 63.2 & 65.7 & 36.8 & 67.2 & 57.7 & 58.9 & 68.0 & 55.4 \\
\hline & PV132 & 62.9 & 67.2 & 38.9 & 67.4 & 53.8 & 59.8 & 67.2 & 53.3 \\
\hline
\end{tabular}

full-length nt sequences of RNA-1 and RNA-2 of 29 BBWV2 isolates were analyzed using RDP, GENECONV, BOOTSCAN, MaxChi, Chimaera, and SISCAN methods implemented in the RDP3 program with a highest acceptable P-Value set to 0.01 . The analyses detected two recombination events in the analyzed BBWV population (Table 6). As expected from the phylogenetic analyses, one recombination event in RNA-1 genome was found to be occurred in the isolate $\mathrm{K}$ (Table 6). $\mathrm{K}$ was detected as a recombinant between XJ14-3 as a major parent and MB7 as a minor parent. In this recombination event, the genomic region (nt 286-2142) of XJ14-3 was replaced with the homologous region of MB7. In addition, the other recombination event was detected in the RNA-2 genome of XJ14-3, which was found to be a recombinant between $\mathrm{K}$ as a major parent and IP as a minor parent. This result could explain why XJ14-3 and IP belonged to the same group in the MP amino acid-based phylogenetic tree. However, no recombination events were found in the BBWV2 Korean isolate population. Therefore, it is likely that genetic exchange by recombination is infrequent in natural populations of BBWV2.

On the other hand, out of 29 isolates, sixteen isolates were analyzed as reassortments (Table 7). This result is in agreement with the phylogenetic grouping by the groupcombinations between RNA-1 and RNA-2 segments (i.e. three genetic subpopulations, GS-I, GS-II and GS-III). Four isolates (BB2, RP, IP, and ME), which belonged to GS-I, were reassortants having RNA-1 of the isolate SP (as a parental isolate of RNA-1) and RNA-2 of the isolate P2 (as 
Table 5. The nucleotide and amino acid sequence identities (\%) between RNA-2 of the BBWV2 Korean isolate BB2 and RNA-2 of other BBWV isolates

\begin{tabular}{|c|c|c|c|c|c|c|c|}
\hline Virus & Isolate & $\begin{array}{l}\text { full genome } \\
\text { (nt) }\end{array}$ & $\begin{array}{l}\text { 5' NCR } \\
\text { (nt) }\end{array}$ & $\begin{array}{l}\text { MP } \\
\text { (aa) }\end{array}$ & $\begin{array}{l}\text { LCP } \\
\text { (aa) }\end{array}$ & $\begin{array}{l}\text { SCP } \\
\text { (aa) }\end{array}$ & $\begin{array}{c}3^{\prime} \mathrm{NCR} \\
\text { (nt) }\end{array}$ \\
\hline \multirow{28}{*}{ BBWV2 } & BB5 & 79.7 & 73.8 & 85.8 & 93.5 & 93.9 & 75.1 \\
\hline & BB9 & 79.5 & 73.2 & 86.2 & 93.3 & 94.4 & 74.9 \\
\hline & $\mathrm{P} 2$ & 79.8 & 72.7 & 86.7 & 91.8 & 93.4 & 75.4 \\
\hline & P3 & 79.9 & 72.3 & 86.7 & 93.8 & 93.9 & 75.4 \\
\hline & SP & 79.9 & 72.7 & 86.9 & 94.0 & 93.9 & 75.4 \\
\hline & SP1 & 79.6 & 72.5 & 86.2 & 93.5 & 93.9 & 74.3 \\
\hline & SP2 & 79.6 & 72.5 & 85.8 & 93.8 & 93.9 & 75.4 \\
\hline & RP1 & 79.6 & 70.0 & 86.9 & 92.6 & 93.9 & 76.5 \\
\hline & $\mathrm{RP} 2$ & 79.3 & 70.4 & 86.2 & 93.3 & 93.9 & 76.5 \\
\hline & RP3 & 79.1 & 70.5 & 86.0 & 92.8 & 93.9 & 75.4 \\
\hline & RP4 & 79.3 & 71.7 & 86.9 & 93.5 & 93.9 & 74.3 \\
\hline & RP5 & 79.7 & 72.0 & 87.5 & 93.8 & 92.9 & 75.4 \\
\hline & RP6 & 79.8 & 71.7 & 86.5 & 94.5 & 93.4 & 73.7 \\
\hline & RP7 & 90.9 & 85.3 & 94.6 & 97.5 & 97.5 & 86.9 \\
\hline & PAP1 & 79.7 & 72.3 & 86.2 & 93.8 & 93.4 & 76.0 \\
\hline & PAP2 & 79.5 & 71.5 & 86.2 & 94.3 & 92.9 & 76.0 \\
\hline & PAP3 & 79.9 & 72.3 & 86.2 & 94.3 & 93.4 & 75.0 \\
\hline & GP2 & 79.3 & 71.2 & 86.7 & 94.3 & 93.4 & 76.0 \\
\hline & GP4 & 79.3 & 71.2 & 86.7 & 94.3 & 93.4 & 76.0 \\
\hline & GP5 & 79.2 & 71.2 & 86.7 & 94.0 & 93.4 & 75.4 \\
\hline & IP & 91.4 & 88.6 & 95.7 & 98.0 & 97.5 & 86.8 \\
\hline & ME & 87.4 & 78.8 & 92.3 & 93.8 & 93.4 & 66.3 \\
\hline & IA & 78.6 & 73.3 & 84.1 & 93.8 & 90.9 & 74.0 \\
\hline & MB7 & 78.9 & 71.2 & 84.7 & 94.0 & 92.4 & 72.8 \\
\hline & PatMMV & 78.9 & 71.6 & 86.2 & 85.1 & 91.9 & 73.5 \\
\hline & B935 & 79.1 & 72.0 & 86.1 & 93.8 & 91.9 & 75.4 \\
\hline & XJ14-3 & 81.6 & 70.7 & 92.0 & 93.3 & 92.9 & 71.4 \\
\hline & $\mathrm{K}$ & 78.6 & 68.2 & 88.8 & 93.5 & 92.9 & 69.9 \\
\hline \multirow{2}{*}{ BBWV1 } & Ben & 59.1 & 58.8 & 52.4 & 63.4 & 59.4 & 50.0 \\
\hline & PV132 & 58.4 & 62.4 & 53.1 & 63.7 & 57.9 & 51.4 \\
\hline
\end{tabular}

Table 6. Recombination in the BBWV2 population detected by recombination detection programs

\begin{tabular}{|c|c|c|c|c|}
\hline Genome & Recombination site & Recombinant & Parental isolates $^{\mathrm{a}}$ & RDP3 (P-value) ${ }^{b}$ \\
\hline RNA1 & nt 286-2142 & $\mathrm{K}$ & $\mathrm{XJ} 14-3 \times \mathrm{MB} 7$ & RGBMCS $\left(7.8 \times 10^{-69}\right)$ \\
\hline RNA2 & nt 484-1399 & $\mathrm{XJ} 14-3$ & $\mathrm{~K} \times \mathrm{IP}$ & $\operatorname{RGBMCS}\left(3.3 \times 10^{-33}\right)$ \\
\hline
\end{tabular}

${ }^{a}$ Parental isolatested by recombination deteclate among analyzed isolates; Major parent $\times$ minor parent.

${ }^{b}$ RDP3-implemented methods supporting the corresponding recombination sites; R (RDP), G (GENECONV), B (BOOTSCAN), M (MAXCHI), $\mathrm{C}$ (CHIMAERA), and S (SISCAN). The reported $P$-value in parentheses is the greatest $P$-value among the calculated $P$-values using RDP3implemented methods and the corresponding method is shown boldface.

a parental isolate of RNA-2). Five isolates (BB5, P2, P3, RP3, and B935), which belonged to GS-II, were reassortments having RNA-1 of XJ14-3 and RNA-2 of SP as parental isolates. PatMMV was found to have MB7 RNA-1 and IA RNA-2 as parental isolates. Six isolates out of 15, which belonged to GS-III, were determined as reassortants between the isolates in the same group GS-III. In conclusion, our results suggest strongly that reassortment is a major evolutionary force in the genetic diversification of BBWV2 population in Korea. 
Table 7. Reassortment in the BBWV2 population detected by recombination detection programs

\begin{tabular}{|c|c|c|c|}
\hline \multirow{2}{*}{ Reassortant $t^{\mathrm{a}}$} & \multicolumn{2}{|c|}{ Parental isolates ${ }^{\mathrm{b}}$} & \multirow{2}{*}{ RDP3 (P-value) ${ }^{c}$} \\
\hline & RNA1 & RNA2 & \\
\hline BB2, RP7, IP, ME & $\mathrm{SP}$ & Unknown (P2) & RGBMCS $\left(3.2 \times 10^{-247}\right)$ \\
\hline BB5, P2, P3, RP3, B935 & XJ14-3 & SP & $\operatorname{RGBMCS}\left(5.4 \times 10^{-142}\right)$ \\
\hline PatMMV & MB7 & IA & $\operatorname{RBMCS}\left(5.0 \times 10^{-30}\right)$ \\
\hline SP, PAP1 & RP6 & PAP3 & $\operatorname{RGBMCS}\left(9.1 \times 10^{-21}\right)$ \\
\hline $\mathrm{SP} 1, \mathrm{SP} 2^{\mathrm{d}}$ & RP1 & Unknown (RP2) & $\operatorname{RMCS}\left(6.4 \times 10^{-12}\right)$ \\
\hline BB9 ${ }^{\mathrm{e}}$ & SP1 & RP6 & $\mathbf{M C}\left(2.4 \times 10^{-18}\right)$ \\
\hline PAP2 & BB9 & SP & $\operatorname{RGBMCS}\left(2.1 \times 10^{-27}\right)$ \\
\hline
\end{tabular}

${ }^{a}$ Some reassortants seemed to be ion programshe corresponding method is shown boldface. (Gd, ome reassortants seemed to be ion programshe corresponding me; e, reassortants seemed to be ion programshe $\mathrm{c} 3$ methods.

${ }^{b} \mathrm{e}$, reassortants seemed to be ion programshe $\mathrm{c} 3$ methodsing method is sho

${ }^{c}$ RDP3-implemented methods supporting the corresponding reassortments; R (RDP), G (GENECONV), B (BOOTSCAN), M (MAXCHI), C (CHIMAERA), and S (SISCAN). The reported $P$-value in parentheses is the greatest $P$-value among the calculated $P$-values using RDP3-implemented methods and the corresponding method is shown boldface.

\section{Discussion}

Major sources of evolution of plant RNA viruses are known as recombination that occurs in either segmented or unsegmented viruses and reassortment that occurs only in viruses with segmented RNAs, as well as mutation that accumulates by error prone replication mechanism (GarciaArenal et al., 2001; Worobey et al., 1999). Recombination has been observed in many plant viruses, such as luteoviruses (Gibbs, 1995), bromoviruses (Allison et al., 1989), nepoviruses (Le Gall et al., 1995), cucumoviruses (Fraile et al., 1997), comoviruses (Zhang et al., 2007; Boulila, 2007), and potyviruses (Seo et al., 2009; Jonson et al., 2009). The potential involvement of recombination in evolution of BBWV2 was reported by Ferrer et al. (2011) based on phylogenetic analyses of partial sequences of BBWV2 isolates collected from various regions.

In this study, we sought to investigate the possible origin, diversity, and genetic structure of BBWV2 Korean population by analyzing full genome sequences of BBWV2 isolates. To this end, we have determined complete genome sequences of $21 \mathrm{BBWV} 2$ isolates collected from various host plants and analyzed their genetic diversity by comparing with previously reported sequences of 8 BBWV2 isolates (Tables 1 and 2). Based on phylogenetic analyses, BBWV2 Korean isolates were divided into two groups for RNA-1 and RNA-2 segments, respectively (Fig. 3). Most of the Korean isolates, excluding BB2 and RP7, subgrouped into II-a together with B935. The Group II-a isolates could be further divided according to the collected areas rather than their host plants. For example, SP isolated from spinach in Jangheung had $99 \%$ nt sequence identity with P2 and P3 isolated from pea in Jangheung, while SP had 93\% identity with SP1 and SP2 isolated from spinach in Geo- mundo. Phylogenetic trees reconstructed using amino acid sequences of the mature proteins (excluding Co-Pro and MP) showed consistent grouping compared with the nt sequence-based trees (Fig. 4). Especially, isolates $\mathrm{K}$ and XJ14-3 showed high nt identities of $90-91 \%$ and amino acid identities of $97-100 \%$ in the same group, but they showed relatively low amino acid identities of $84 \%$ and $92 \%$ for amino acid sequences of Co-Pro and MP, respectively, and were grouped separately (Fig. 4).

One of the remarkable features of the BBWV2 Korean isolates compared to the previously reported isolates was group-combination between RNA-1 and RNA-2 segments. The isolates composed of Group I RNA-1 and Group II RNA-2 were predominant in Korea. Group-combination between RNA segments that belong to different groups could be explained by reassortment. To confirm the result of phylogenetic analyses, we investigated whether recombination and reassortment have occurred in BBWV2 population using the RDP3 program. Only two recombination events were detected in the analyzed BBWV2 population: One at Co-Pro and NTBM regions of RNA-1 of Korean isolate $\mathrm{K}$ and another one at MP region of RNA-2 of Chinese isolate XJ14-3 (Table 6). No recombination events were found in BBWV2 Korean isolates. The relatively high sequence variation in Co-Pro and MP regions suggests that these regions are under looser evolutionary constraints and vulnerable to mutation and recombination. In addition, our phylogenetic analyses indicate that the isolates collected in Korea during the years 2006-2012 might not be originated from the Korean isolate $\mathrm{K}$ reported in 2000.

Meanwhile, 16 isolates out of 29 were found to be reassortants (Table 7). This result is highly consistent with group-combination based subpopulation of GS-I, GS-II and GS-III. Four GS-I isolates (BB2, RP7, IP and ME) were 


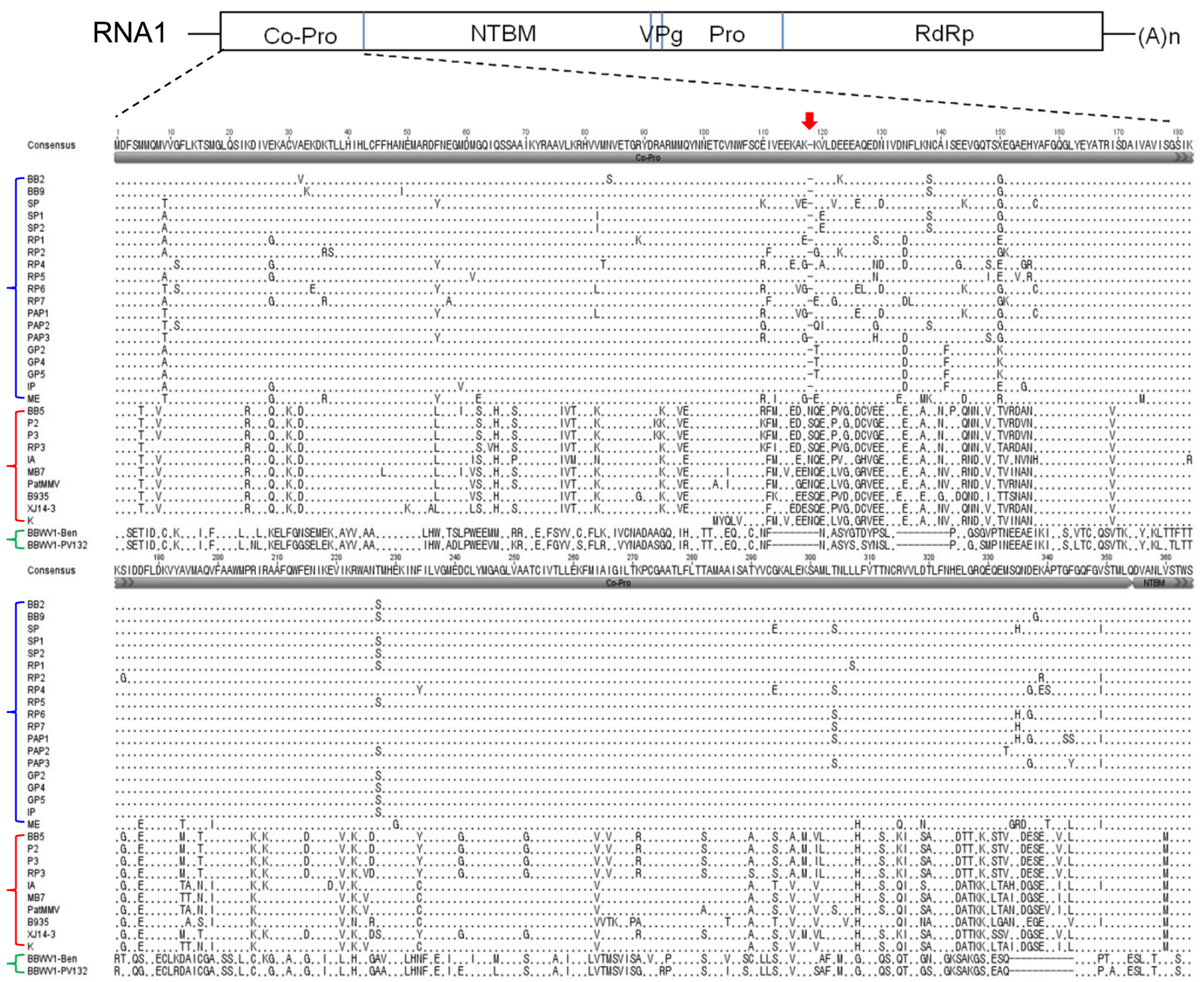

Fig. 5. Alignment of the amino acid sequences of Co-Pro of the BBWV2 isolates. Sequences were aligned by the geneious method. Same amino acid sequences are indicated with a ' '. Arrow indicates the amino acid position 118 on the polyprotein precursor.

reassortments having SP RNA-1 and P2 RNA-2, and five GS-II isolates (BB5, P2, P3, RP3 and B935) were reassortments having XJ14-3 RNA-1 and SP RNA-2. Six Korean isolates belonged to GS-III were determined as reassortments between the Korean isolates in the same group GSIII (Table 7). Japanese isolate PatMMV, which was detected as a reassortant, might be originated by reassortment between Japanese isolates (i.e. MB7 and IA). Collectively, our results revealed that BBWV2 Korean isolates have been evolved mainly by reassortment rather than recombination. In the case of Bean pod mottle virus (BPMV; genus Comovirus) having similar genome structures with BBWV2, reassortment events between distinct BPMV strains and recombination events at the putative helicase region of RNA-1 were reported (Zhang et al., 2007). In addition, Co-
Pro and the C-termainal domain of the putative helicase of BPMV were identified as symptom severity determinants (Gu et al., 2005). Since we also found high sequence variations in Co-Pro (Fig. 5), it is worthy to examine whether Co-Pro of BBWV2 is also a pathogenicity determinant in the BBWV2-pepper pathosystem. In the present study, we have analyzed the genetic diversity and structure of the BBWV2 population mainly collected from East Asia. Our findings revealed that reassortment occurred naturally in the BBWV2 population, and might play an important role in disease incidence occurred recently in Korea. Further analyses of genetic population structure of BBWV2 with more diverse full-genome sequences of worldwide isolates will be required for in-depth understanding of the evolutionary history of BBWV2. 


\section{Acknowledgements}

This research was carried out with the support of "Cooperative Research Program for Agricultural Science \& Technology Development (Project No. PJ00651901)" of the Rural Development Administration and iPET (Korea Institute of Planning and Evaluation for Technology in Food, Agriculture, Forestry, and Fisheries: No. 110034-05-3-HD110), Ministry for Food, Agriculture, Forestry, and Fisheries, Republic of Korea.

\section{References}

Allison, R. F., Janda, M. and Ahlquist, P. 1989. Sequence of cowpea chlorotic mottle virus RNAs 2 and 3 and evidence of a recombination event during bromovirus evolution. Virology 172:321-330.

Benner, C. P., Kuhn, C. W., Demski, J. W., Dobson, J. W., Colditz, P. and Nutter, F. W., Jr. 1985. Identification and incidence of pepper viruses in Northeastern Georgia. Plant Dis. 69:9991001.

Boulila, M. 2007. Phylogeny and genetic recombination of Grapevine fanleaf virus isolated from naturally infected vineyards in Tunisia. Phytopathol. Mediterr. 46:285-294.

Brunt, A. A., Crabtree, K., Dallwitz, M. J., Gibbs, A. J. and Watson, L. 1996. Viruses of Plants. Descriptions and Lists from the VIDE Database. CAB International, Wallingford, UK.

Chang, M. U. and Chung, J. D. 1987. Studies on viruses isolated from Lilium spp. in Korea. Plant Pathol. J. 3:223-235.

Cho, J. D., Kim, J. S., Lee, S. H., Choi, G. S. and Chung, B. N. 2007. Viruses and symptoms on peppers and their infection types in Korea. Res. Plant Dis. 13:75-81 (in Korean).

Choi, H. S., Cho, J. D., Lee, K. H. and Kim, J. S. 2001. Broad bean wilt fabaviruses and their specific ultrastructures. Kor. J. Electron Microscopy 31:215-222.

Ferrer, R., Ferriol, I., Gueri, J., Moreno, P. and Rubio, L. 2011. Genetic variation and evolutionary analysis of Broad bean wilt virus 2. Arch. Virol. 156:1445-1450.

Fraile, A., Alonso-Prados, J. L., Aranda, M. A., Bernal, J. J., Malpica, J. M. and Garcia-Arenal, F. 1997. Genetic exchange by recombination or reassortment is infrequent in natural populations of a tripartite RNA plant virus. J. Virol. 71:934-940.

Garcia-Arenal, F., Fraile, A. and Malpica, J. M. 2001. Variability and genetic structure of plant virus populations. Annu. Rev. Phytopathol. 39:157-186.

Gibbs, M. J., Armstrong, J. S. and Gibbs, A. J. 2000. Sister-scanning: a Monte Carlo procedure for assessing signals in recombinant sequences. Bioinformatics 16:573-582.

Goldbach, R., Martelli, G. P. and Milne, R. G. 1995. Family Comoviridae. In: Virus taxonomy. Classification and nomenclature of viruses. Sixth report of the International Committee on Taxonomy of Viruses, ed. by F. A. Murphy, C. M. Fauquet, D. H. L. Bishop, S. A. Ghabrial, A. W. Jarvis, G. P. Martelli, M. A. Mayo and M. D. Summers, pp 341-347. Springer, Wien New York, (Arch Virol [Suppl] 10).
Gu, H. and Ghabrial, S. A. 2005. The Bean pod mottle virus proteinase cofactor and putative helicase are symptom severity determinants. Virology 333:271-283.

Hahm, Y. I., Kwon, M., Kim, J. S., Seo H. W. and Ahn, J. H. 1998. Serveys on disease occurrence in major horticultural crops in Kangwon Alpine areas. Plant Pathol. J. 14:668-675.

Ikegami, M., Kawashima, H., Natsuaki, T. and Sugimura, N. 1998. Complete nucleotide sequence of the genome organization of RNA2 of Patchouli mild mosaic virus, a new fabavirus. Arch. Virol. 143:2431-2434.

Ikegami, M., Onobori, Y., Sugimura, N. and Natsuaki, T. 2001. Complete nucleotide sequence and the genome organization of Patchouli mild mosaic virus RNA1. Intervirology 44:355358.

Jonson, M. G., Seo, J. K., Choi, H. S., Kim, J. S. and Kim, K. H. 2009. Effects of Recombination on the pathogenicity and evolution of Pepper mottle virus. Plant Pathol. J. 25:417-421.

Kobayashi, Y. O., Mikoshiba, Y., Honda, Y. and Omura, T. 2004. Detection of Broad bean wilt virus 1 and Broad bean wilt virus 2 in Japan. Ann. Rept. Kanto Plant Prot. Soc. 51:43-48.

Kobayashi, Y. O., Nakano, M., Kashiwazaki, S., Naito, T., Mikoshiba, Y., Shiota, A., Kameya-Iwaki, M. and Honda, Y. 1999. Sequence analysis of RNA-2 of different isolates of broad bean wilt virus confirms the existence of two distinct species. Arch. Virol. 144:1429-1438.

Kobayashi, Y. O., Kobayashi, A., Nakano, M., Hagiwara, K., Honda, Y. and Omura, T. 2003. Analysis of genetic relations between Broad bean wilt virus 1 and Broad bean wilt virus 2 . J. Gen. Plant Pathol. 69:320-326.

Kobayashi, Y. O., Nakano, M., Kashiwazaki, S., Naito, T., Mokoshiba, Y., Shiota, A., Kameya-Iwaki, M. and Honda, Y. 1999. Sequence analysis of RNA-2 of different isolates of broad bean wilt virus confirms the existence of two distinct species. Arch. Virol. 144:1429-1438.

Koh, L. H., Cooper, J. I. and Wong, S. M. 2001. Complete sequences and phylogenetic analyses of a Singapore isolate of Broad bean wilt fabavirus. Arch. Virol. 146:135-147.

Kondo, T., Fuji, S., Yamashita, K., Kang, D. K. and Chang, M. U. 2005. Broad bean wilt virus 2 in yams. J. Gen. Plant Pathol. 71:441-443.

Kuroda, T., Okumura, A., Takeda, L., Miura, Y. and Suzuki, K. 2000. Nucleotide sequence and synthesis of infectious RNA from cloned cDNA of Broad bean wilt virus 2 RNA 2. Arch. Virol. 145:787-793.

Kwak, H. R., Kim, M. K., Nam, M., Kim, J. S., Kim, K. H., Cha, B. and Choi, H. S. 2013. Genetic compositions of Broad bean wilt virus 2 infecting red pepper in Korea. Plant Pathology J. (in press).

Lee, U., Hong, J. S., Choi, J. K., Kim, K. C., Kim, Y. S., Curtis, I. S., Nam, H. G. and Lim, P. O. 2000. Broad bean wilt virus causes necrotic symptoms and generates defective RNAs in Capsicum annuum. Phytopathology 90:1390-1395.

Lee, S. H., Lee, K. W. and Chung, B. J. 1979. Investigations on the virus diseases in spinach (Spinacia oleracea L.) 2. Identification of Broad bean wilt virus occuring spinach. Kor. J. Plant Port. 18:11-14. 
Le Gall, O., Candresse, T. and Dunez, J. 1995. Transfer of the 39 non-translated region of grapevine chrome mosaic virus RNA1 by recombination to tomato black ring virus RNA-2 in pseudorecombinant isolates. J. Gen. Virol. 76:1285-1289.

Lisa, V. and Boccardo, G. 1996. Fabaviruses: broad bean wilt and allied viruses. In: The plant viruses, vol. 5: Polyhedral virions and bipartite RNA genomes, ed. by B. D. Harrison and A. F. Murant, pp. 229-250. Plenum Press, New York.

Nakamura, S., Iwai, T. and Honkura, R. 1998. Complete nucleotide sequence and genome organization of Broad bean wilt virus 2. Ann. Phytopathol. Soc. Jpn. 64:565-568.

Park, I. S., Kim, K. W., Kyun, H. J. and Chang, M. U. 1998. The viruses in gladiolus hybridus cultivated in Korea 2. Broad bean wilt virus, Cucumber mosaic virus and Tobacco rattle virus. Plant Pathol. J. 14:83-91.

Qi, Y., Zhou, X. and Li, D. 2000a. Complete nucleotide sequence and infectious cDNA clone of the RNA1 of a Chinese isolate of Broad bean wilt virus 2. Virus Genes 20:201-207.

Qi, Y., Zhou, X., Xue, C. and Li, D. 2000b. Nucleotide sequence of RNA2 and polyprotein processing sites of a Chinese isolate of Broad bean wilt virus 2. Prog. Nat. Sci. 10:680-686.

Roh, S. H. and Chang, M. U. 1998. Three viruses isolated from Gentiana spp. in Korea. Plant Pathol. J. 14:425-432.

Ryu, J. G., Ko, S. J., Lee, Y. H., Kim M. K., Kim K. H., Kim H. T. and Choi, H. S. 2009. Incidence and distribution of virus disease on paprika (Capsicum annuum var. grossum) in Jeonnam province of Korea. Plant Pathol. J. 25:95-98.

Seo, J. K., Ohshima, K., Lee, H. G., Son, M., Choi, H. S., Lee, S.
H., Sohn, S. H. and Kim, K. H. 2009. Molecular variability and genetic structure of the population of Soybean mosaic virus based on the analysis of complete genome sequences. Virology 393:91-103.

Sui, C., Wei, J. H., Zhan, Q. Q. and Zhang, J. 2009. First report of Broad bean wilt virus 2 infecting Bupleurum chinense in China. Plant Dis. 93:844.

Tamura, K., Peterson, D., Peterson, N., Stecher, G., Nei, M. and Kumar, S. 2011. MEGA5: Molecular evolutionary genetics analysis using maximum likelihood, evolutionary distance, and maximum parsimony methods. Mol. Biol. Evol. 28:27312739.

Taylor, R. H. and Stubbs, L. L. 1972. Broad bean wilt virus. Page 81 in: Description of Plant Viruses. Commonw. Mycol. Inst./ Assoc. Appl. Biol., Warwick, U.K.

Uyemoto, K. J. and Provvidenti, R. 1974. Isolation and identification of two serotypes of Broad bean wilt virus. Phytopathology 64:1547-1548.

Watterson, J. C. 1993. Development and breeding of resistance to pepper and tomato viruses. In: Resistance to Viral Diseases of Vegetables, ed. by M. M. Kyle, pp. 80-101.Timber Press, Portland OR.

Worobey, M. and Holmes, E. C. 1999. Evolutionary aspects of recombination in RNA viruses. J. Gen. Virol. 80:2535-2543.

Zhang, C., Gu, H. and Ghabrial, S. A. 2007. Molecular characterization of naturally occurring RNA1 recombinants of the Comovirus Bean pod mottle virus. Phytopathology 97:12551262. 